\title{
PAISAGENS, REALIDADE E IMAGINÁRIO: A PERCEPÇÃO DO COTIDIANO *
}

VICENTE DEL RIO

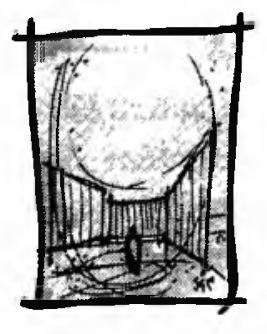

\section{RESUMO}

Nosso cotidiano se conforma e realiza através da percepção de paisagens, num amálgama entre realidade e imaginário. São comentadas cinco áreas de pesquisa dos processos perceptivos, desde a psicologia terapêutica à informatização das relações espaciais, que podem ajudar a compreender nossas relações com a paisagem e nossa representações dela.

\section{ABSTRACT}

We shape and realize our daily life through the perception of landscapes, in a merge between reality and imagination. Five research areas of the processes of perception are commented, from therapeutic psicology to the informatization of spatial relations, that may help us in understanding our relationship with the landscape and their representations.

Popularmente, entende-se paisagem como um conjunto de elementos naturais moldando uma vista, geralmente distante e que se impõe ao observador com conotações positivas. "Olhem que paisagem linda..." é uma expressão típica de quem viaja. Mas, para os estudiosos paisagem quer dizer muito mais. Para cada área disciplinar que se interessa pelo meio ambiente que nos envolve e nossas relações com ele, a palavra paisagem é mágica. Arquitetos, urbanistas, geógrafos, paisagistas, escritores, agrônomos, biólogos, engenheiros de transporte, sociólogos e tantos outros, querem produzir, moldar, estudar, complementar, descrever, destruir, conservar, usar, se apropriar da paisagem dela, enfim.

Só que nossas formações acadêmico-profissionais lançam mão de conceitos diferentes do que seja A PAISAGEM, com maiúsculas; aquela que molda a história, participa do destino da humanidade. Isto nos conduz a estudos, metodologias e objetivos acadêmicos distintos. Para o arquiteto, a paisagem ideal é uma bela edificação; para o urbanista pode ser uma cidade bonita e socialmente justa; para o geógrafo, ela é um lugar cultural; o biólogo a vê como ecossistema que deve estar em equilibrio; para o antropólogo, o cenário de uma vida; para o arqueólogo, o de uma civilização. 
Evidente que as paisagens tomadas assim, com óticas diferentes, não são completas ou plenamente verdadeiras. Com a exacerbação da compartimentação do saber nos tempos modernos, as paisagens, ou melhor, a paisagem, sofreu. As visōes parciais levam, muitas vezes, a posturas equivocadas $e$, infelizmente, o homem ainda não tomou plena consciência disto; as resultantes de nossas relações e interferências com a paisagem estão aí para demonstrar tantos equívocos.

Cada vez mais, entende-se que essas distintas visões da paisagem são complementares, nenhuma pode sobreviver sozinha, mesmo se há instâncias em que uma visão deve acabar tendo prevalência sobre outras. A paisagem dever ser entendida como o cenário que nos rodeia, participa e conforma o nosso cotidiano. Até a economia política marxista já admite que a paisagem não é um simples subproduto da luta de classes, mas que participa desta luta e influencia as relações sociais se apenas por sua inércia históricofuncional como fato físico. Hoje busca-se um conceito de paisagem mais holístico, compondo-se os mais diferentes olhares sobre a paisagem, de forma a compreendê-la desde diversos pontos de vista, complementares e indispensáveis.

Mas será que, dentro desta vontade toda de entender paisagem holisticamente, existiria alguma forma de categorização que não acabasse por minar a própria idéia de todo que defendemos para a compreensão da paisagem? Será que existem categorias tão complementares e tão interdependentes que a mera existência de uma pressupõe a existência da outra? Acredito que são elas as categorias de paisagens reais e paisagens imaginárias. Os mais diversos enfoques com que se tem estudado a paisagem caem sempre dentro de uma ou outra dessas categorias. Paisagem real não existe sem paisagem imaginária, nem vice-versa. Categorização esta percebida por Italo Calvino que a explora em sua obra-prima As cidades invisiveis, onde Marco Polo, com suas estórias sobre cidades que combinam experiência, imaginário e expectativas, moldava a realidade do reino de Kublai Khan.

Desses olhares diversos sobre a paisagem destaca-se a importância da percepção da paisagem, ou percepção ambiental, um tema que tem despertado o interesse de alguns pesquisadores no Brasil. Sabemos que a percepção é o processo mental através do qual nos relacionamos com o mundo, a partir de sensaçōes transmitidas ao cérebro pelos cinco sentidos. Esse processo é seletivo, ou seja, nossa mente conscientiza-se apenas de parte dessas sensações, e a visão é o sentido que mais se destaca. Segundo James Gibson, as sensações são a matéria-prima da experiência humana, enquanto as percepções são o seu produto elaborado ${ }^{1}$ Percebe-se a realidade através de um processo mental ativo, em que nos utilizamos de um leque de informações coletadas e inferidas. Portanto, constantemente, construímos a realidade e a categorização real e imaginária, onde a fronteira nunca é claramente definida.

Daí fica evidente a importância do estudo dos processos perceptivos para se compreender as relações do homem com o mundo e a dita realidade. Nesse sentido, 
nas linhas seguintes, pode-se destacar cinco áreas de interesse que, por sua própria existência e seus objetivos de pesquisa, demostram a importância dos estudos de percepção da paisagem:

1. Primeiramente, destacamos as preocupações mais diretamente ligadas à medicina ou à psicologia terapêutica. Comprovou-se que a percepção ambiental influencia a própria saúde do homem, cujas evidências foram muito bem resumidas em recente artigo da psicóloga Ruth Parsons ${ }^{2}$. Ela mostra que, por um lado, há processos psicológicos ligados a fatores afetivos e preferências ambientais: paisagens e ambientes naturais, por exemplo, têm efeitos positivos sobre a fadiga mental (Fig. 1). Sugere-se até que certos tipos de arranjos ambientais despertam respostas emocionais inatas, herdadas de nossa própria evolução genética. Por outro lado, ela discute evidências neuropsicológicas que ligam os estímulos perceptivos a processos fisiológicos, como as respostas do sistema imunológico.

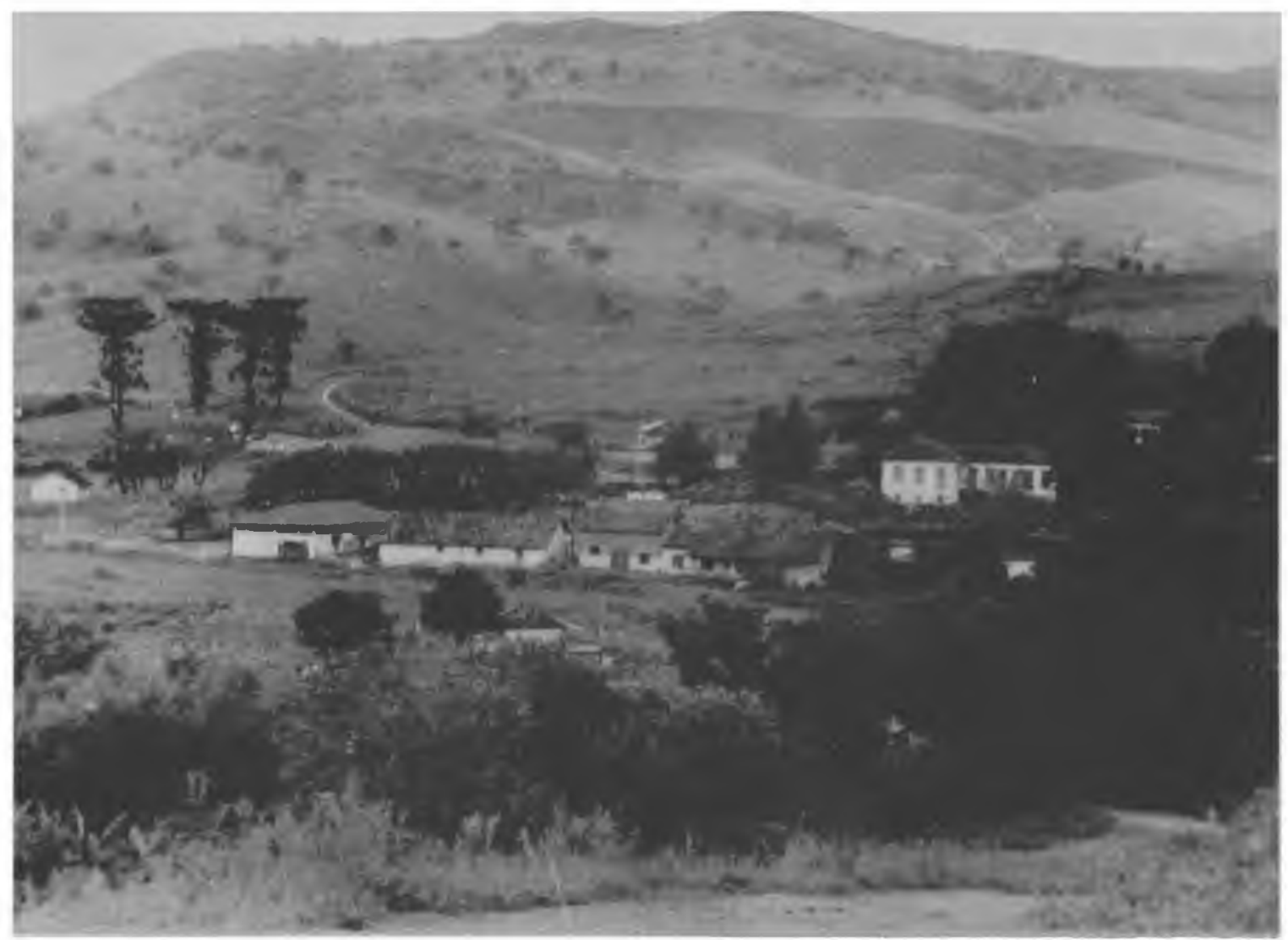

Fig. 1-A percepcāo de paisagens naturais tem efeitos positivos comprovados sobre a saúde mental. (Fazenda em Cambuquira, $M G$ )

2. Em segundo lugar, pode-se destacar os estudos relativos das resultantes das percepções, ou seja, as condutas propriamente ditas. A todo processo perceptivo sucedese uma conduta, que pode ser um comportamento consciente ou uma atitude que, como observa Yi-fu Tuan, é uma postura cultural e uma posição que se toma perante o mundo ${ }^{3}$. 
A importância dos estudos comportamentais, herdeiros do behaviorismo, se destacam quanto à aplicação de suas metodologias de investigação em campo. Eles tentam compreender as inter-relações do homem com os ambientes e as paisagens, admitindo que também esses ambientes e paisagens podem influenciar comportamentos específicos, individuais e de grupo, inconscientes ou conscientes.

As paisagens "povoadas" assumem significados específicos, complementares ou mesmo diferentes dos que inferimos antes de serem apropriadas pelo uso. Os arranjos de assentos em local público podem potencializar a conversa ou não, a projeção de sombra de um prédio define áreas "humanizadas", os atributos físicos de um lugar podem fazer com que ele fique deserto a maior parte do tempo, o desenho de uma calçada pode levar os transeuntes a diferentes experiências perceptivas e definir áreas comportamentais (Fig. 2). Os estudos comportamentais têm assumido grande importância para a programação arquitetônica e urbanística, no sentido de ajudar a prever melhor as respostas humanas aos ambientes construídos.

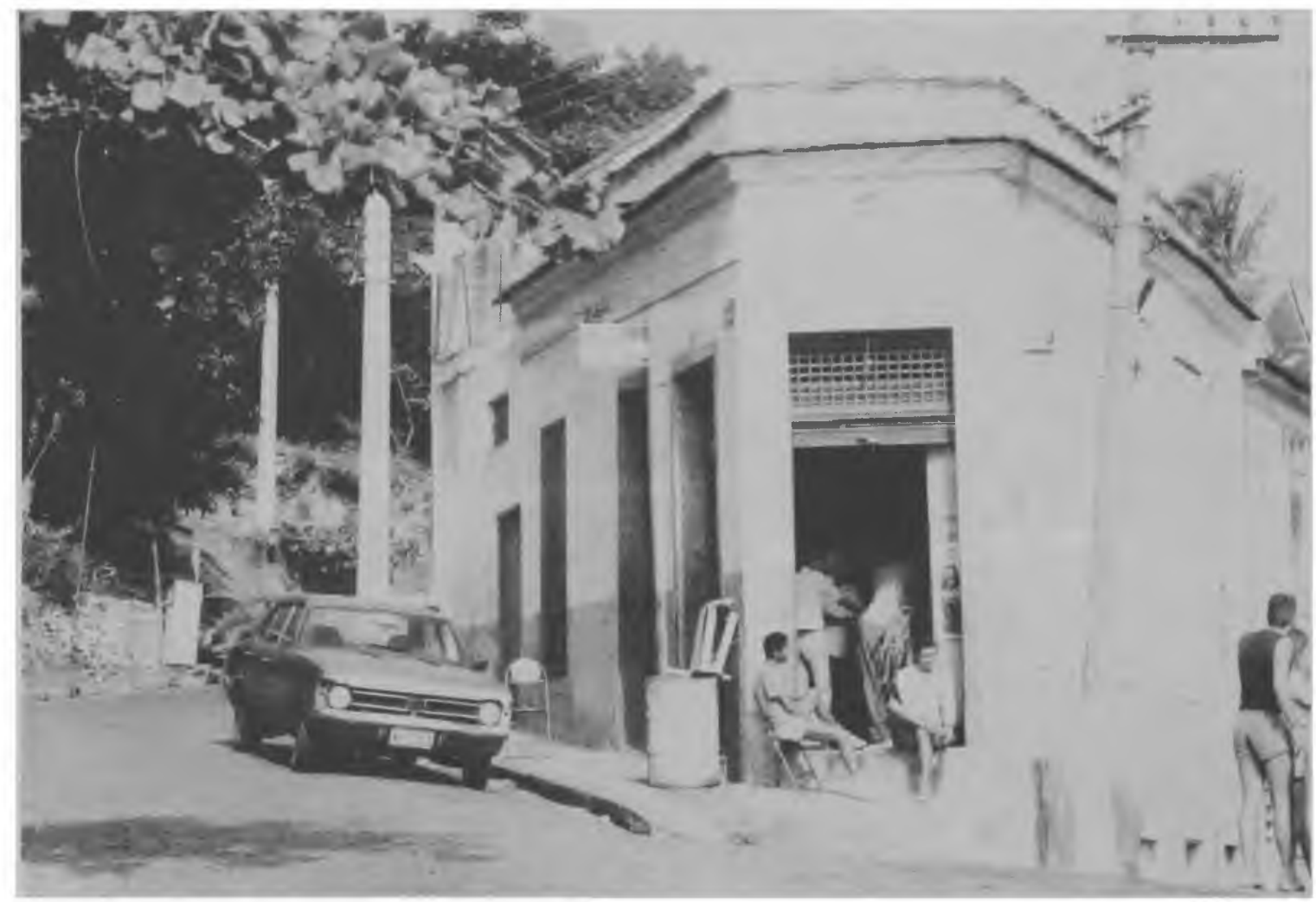

Fig. 2. -A conduta e o comportamento resultam da percepção, ao mesmo tempo que também dão significado às pais'agens: (Esquina no Morro do Pinto, área portuária do Rio de Janeiro)

3. Em terceiro lugar, os estudos de paisagem em que se busca a compreensão das sensações e sentimentos que a conformação do ambiente físico causa ao observador. Neste caso, o pioneiro é o inglês Gordon Cullen com seus estudos de townscape, que categorizou suas sensações como transeunte de espaços urbanos, destacando a importância da topologia e da visão seriada da paisagem ${ }^{4}$ 
A paisagem não é mais vista como um cenário estático mas mutável, que percebemos através de uma sucessão de quadros visuais; portanto, para ser interessante, os quadros devem ser dinâmicos e esconder surpresas, as texturas, significados, vistas e relações visuais devem ser protegidas e ressaltadas (Fig. 3). Muito próximo às preocupações da gestalt, esta linha de pesquisa encontrou paralelos em Kevin Lynch e Donald Appleyard, em seus estudos sobre a percepção da paisagem de auto-estradas ${ }^{5}$

4. Tem se dado destaque especial aos estudos sobre a cognição, propriamente dita: momento do processo perceptivo em que se processa o conhecimento e infere-se significados. Evidentemente, sendo a percepção um processo individual, cada um de nós vê uma paisagem diferente. Não apenas vemos paisagens fisicamente diferentes, por conta de nossas capacidades perceptuais individuais, como suas imagens e

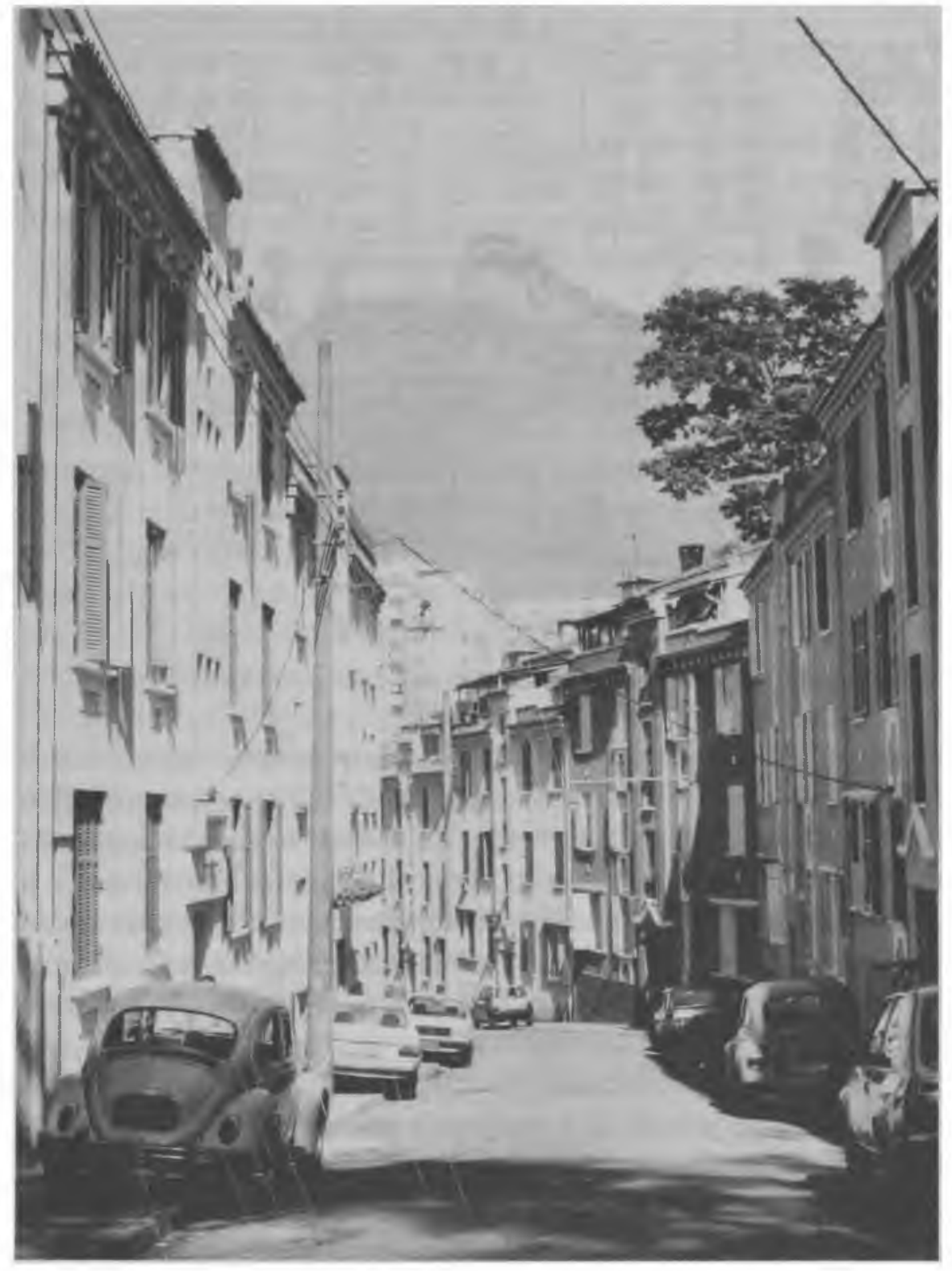

Fig. 3 - A percepçāo de quadros visuais e de relaçöes topológicas geram sensiações' sentimentos. (Rua Pires de Almeida, Cosme Velho, $R J)$ 
significados são diferenciados. São pesquisas que tentam compreender como um ambiente é lembrado, quais de seus atributos compõem a sua imagem mental, sua identidade e legibilidade, como eles se combinam e se estruturam em um mapa mental operacional do lugar (Fig. 4).

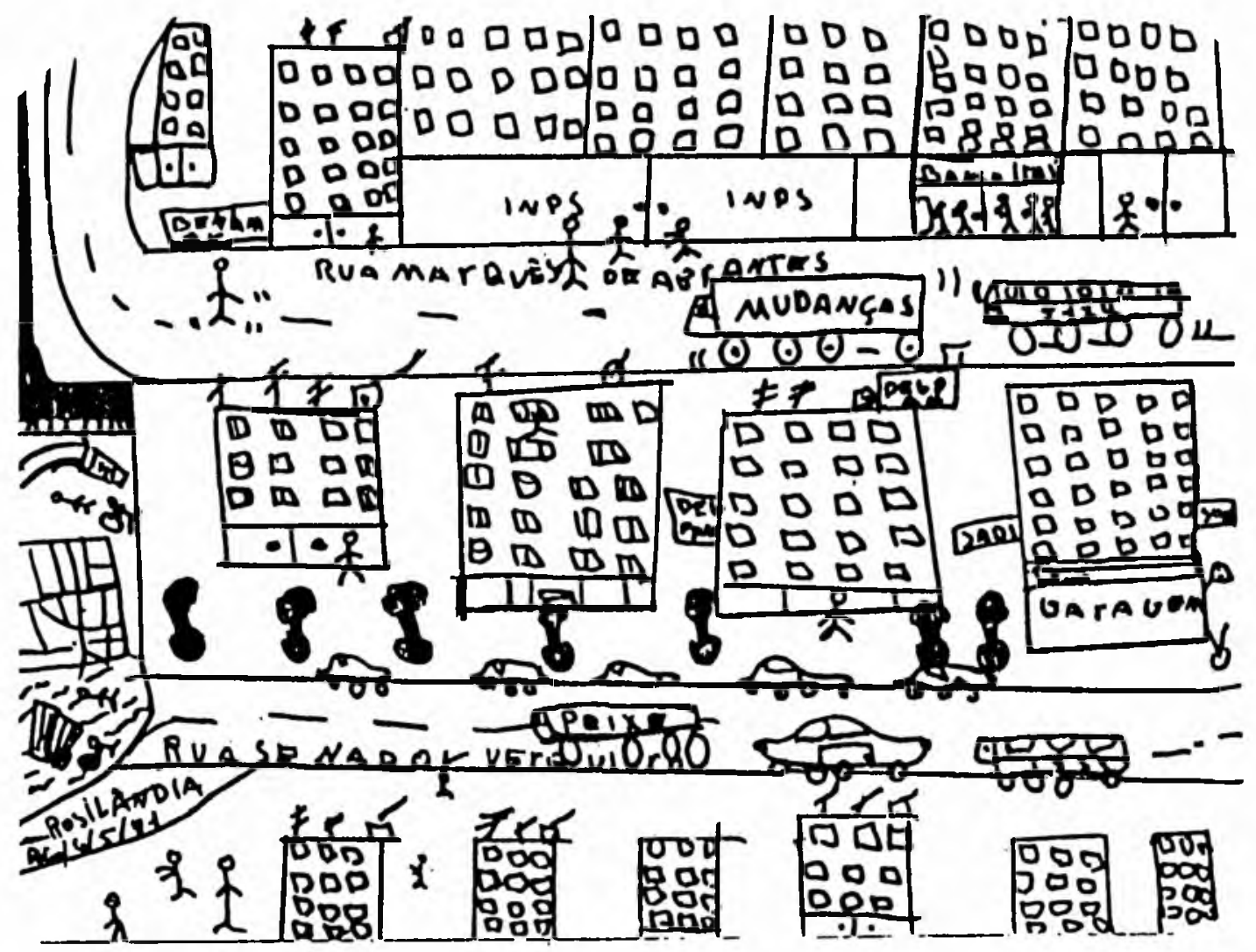

Fig. 4 - Um mapa mental revela a percepção de uma lógica operacional do lugar. (Bairro do Botafogo, RJ)

Dentro dessa temática e concentrando-se nas áreas de arquitetura, urbanismo e geografia, os estudos desenvolvidos no Brasil têm seguido três linhas principais ${ }^{6}$. São elas: a que se fundamenta na obra de Kevin Lynch, a que segue os ensinamentos da semiótica e a que adota uma visão mais holística ao seguir a geografia humanística e a obra de Yi-fu Tuan. O conceito de paisagem acaba confundindo-se com o conceito de lugar; a paisagem vivenciada torna-se lugar enquanto síntese da experiência localizada, incluindo o que imaginamos, as vistas, histórias, sentimentos e conceitos, como afirma Eugene Walter?

Este autor sublinha a importância do sentido do lugar para o homem ao comentar a obra de Sófocles, no contexto da psicanálise e da obra de Freud. Embora muito se tenha explorado a famosa pergunta de Édipo "quem sou eu??", sua outra indagação importante "a que lugar eu pertenço?" não foi enfrentada pela teoria psicoanalítica. Édipo só se 
contenta na última peça de Sófocles, quando retorna à sua cidade natal e finalmente encontra paz de espírito, descobrindo que para conhecer-se a si próprio, deve conhecer o seu verdadeiro lugar; esse, segundo Walter, seria o verdadeiro complexo de Édipo.

No caso específico das cidades e lugares urbanos, destaca-se cada vez mais a grande importância de sua percepção nas definições e no direcionamento do desenvolvimento. Mais do que nunca, está se conscientizando para o poder da imagem da cidade, ou de partes da cidade, em se atrair investimentos em geral; uma questão de evidente destaque para o atual tema da revitalização urbana ${ }^{8}$. A atratibilidade de um lugar urbano, seja em termos de captar residentes, compradores ou investidores e recursos, está diretamente ligada à capacidade e ao significado de sua imagem.

No Brasil, na briga por investimentos através da veiculação e manipulação da imagem da cidade, Curitiba pulou na frente, liderada pelo prefeito Jaime Lerner ${ }^{9}$. A imagem nacional e internacional da cidade é extremamente positiva, ela é descrita pela mídia como "uma cidade que nem parece do Terceiro Mundo" e que "deu certo" numa visão descontextualizada e que não traduz a complexa realidade em que se insere. A imagem de Curitiba é avant-garde e, como dizia Carlos Nelson dos Santos, permite à burguesia dominante um contraponto ao nosso cenário de subdesenvolvimento, um modelo para quando o Brasil "embranquecer e se civilizar"

Um dos problemas nisto é que a imageabilidade desses lugares acaba dependendo menos de seus atributos e qualidades intrínsecas do que pelo modo com que são retratados pela mídia. O perigo está no aumento da importância do marketing de um lugar ou cidade e pelas tendências globais nos padrões de consumo, como vem ocorrendo em países desenvolvidos. O consumismo exacerbado e a concentração em paradigmas limitados têm resultado em imagens ambientais "pasteurizadas", oferecidas onde quer que seja, como nos casos de projetos de revitalização onde se repete modelos e clichês. Proliferam os shopping-malls, - a panacéia capitalista de recuperação de áreas deterioradas, - assim como as paisagens controladas que exploram a imagem de "segurança" dos consumidores e moradores. Como nos lembra Richard Sennet, além desses ambientes não terem graça, eles são neutros e destituídos de tudo que representa verdadeiros contatos sociais, uma vez que as diferenças acabam sendo tomadas como ameaças, não como estímulos ${ }^{10}$.

Além da tendência à homogeneização dos lugares urbanos, as representações e os deslocamentos de diferentes geografias e histórias tornam-se tão ou mais importantes do que a própria realidade (Fig. 5). Exemplo maior é a Disneylandia, o reflexo perfeito da cultura pós-moderna de classe média, que espera uma urbanidade sem ameaça, com sensações previsíveis, apoiada em simulacros e no deslocamento geográfico das autenticidades, de forma a incentivar o fácil consumo de símbolos ${ }^{11}$. Nos EUA e na Europa, lugares históricos têm suas imagens exploradas, transformados em objetos de merchandising; os especuladores imobiliários também já oferecem empreendimentos com caráter histórico "instantâneo" A postura ideológica que se trai na manipulação 
destas imagens é a de um positivismo ingênuo que, embora já admita que as cidades do futuro não se parecerão à utopia de Flash Gordon, ainda não notou que a cidade do futuro já está presente e se parece muito mais com as distopias sugeridas por filmes como Bladerunner e Boys'n the Hood, ou por paisagens como as de Nova York pintadas por Will Eisner, criador do Spirit.

Fig. 5 - Deslocamentos do templo, da percepçāo e da geografia: instant history na era da informática. Desde Disneyworld a esta reprodução da "Torre de Pisa" em Chicago.

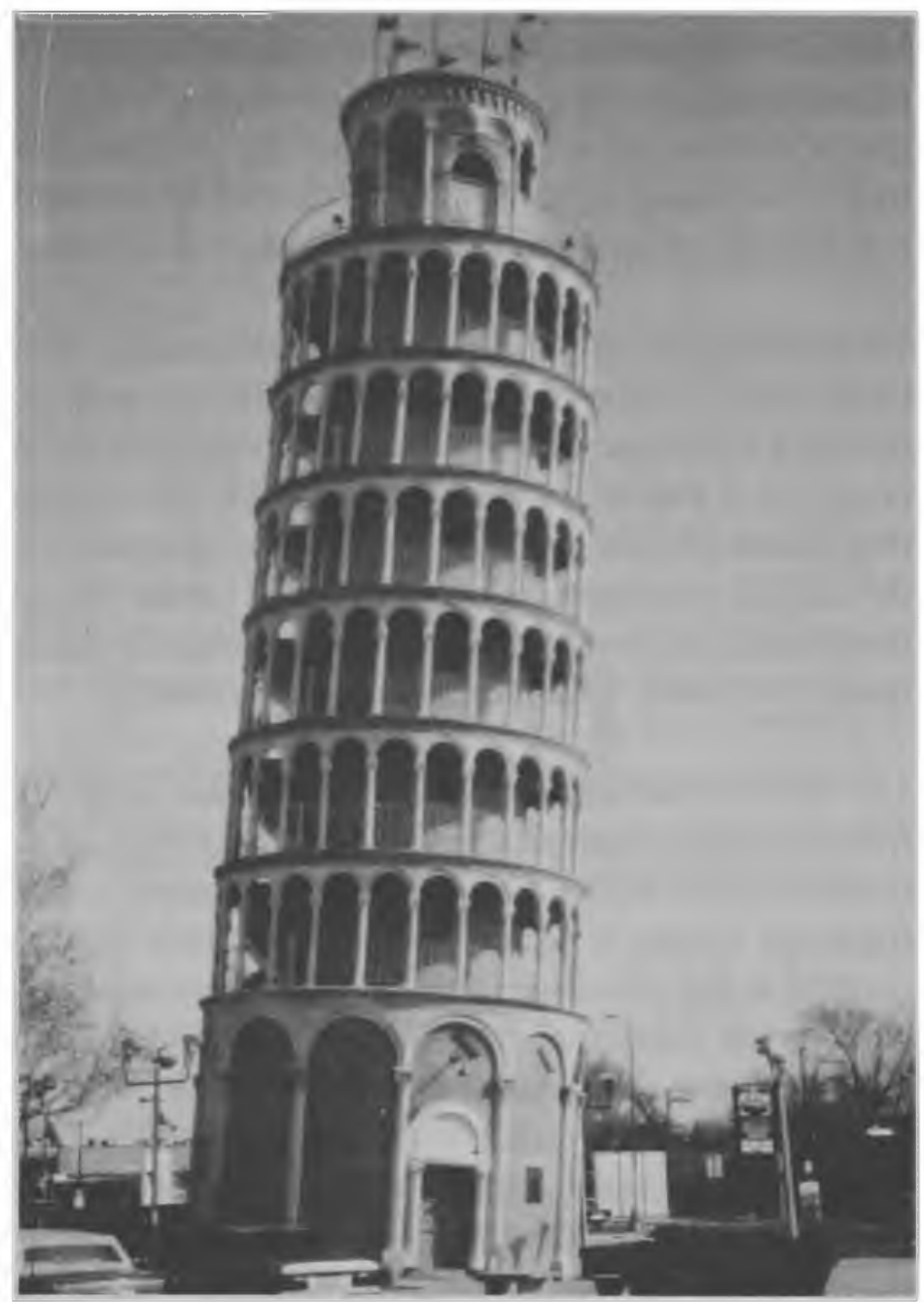

5. Finalmente, deve-se considerar uma questão que se impõe como tendência inevitável da nossa sociedade cada vez mais informatizada, inspirando-nos em trabalhos como os de Michael Sorkin e Paul Virilio. Este, em trabalho recente, discute como a cidade está se tornando um não-lugar, suas paisagens, sua geografia, suas relações físico-espaciais e sociais pulverizadas pelo avanço da informatizaçãa ${ }^{12}$. Uma topologia eletrônica em que as interfaces substituem as relações diretas de percepção. O representante em tela passando a ter mais importância do que o objeto real, pois revela um número ilimitado de informações através dos bancos de dados. Por outro lado, o macro e o micro perdem o seu sentido; o espaço passa a ser visto como aquilo que impede que tudo esteja no mesmo lugar, ao mesmo tempo. Na percepção dessa nova realidade virtual, a única dimensão que fará sentido é o tempo, um tempo de difusão instantânea de informações. 
A questão é, então, procurar compreender a percepção da paisagem e suas imagens para que se informe as ações e se possa lidar conscientemente com condutas e expectativas. Esses estudos podem levar a representações diversas das paisagens reais e imaginárias da população, mas pretende-se que sejam não apenas significantemente representativas mas que sejam imagens públicas ou coletivas. Busca-se o amálgama das representações individuais, ao mesmo tempo tão diferente e tão igual a cada uma delas. Uma paisagem composta de atributos reais e imaginários, utopias e distopias, desejos e medos, sonhos e realidades, perspectivas absurdas e regras enganosas, como diria Calvino. Essa deve ser a nossa utopia, essa será a nossa paisagem: a sobrevivência da espécie humana, pelo menos da maneira como nós a conhecemos, também depende disto.

\section{NOTAS}

Baseado em palestra proferida no Seminário PAISAGEM. PAISAGENS. Uma Visão Interdisciplinar do Estudo da Paisagem, Faculdade de Arquitetura, Artes e Comunicação, UNESP-Bauru (25 a 29/4/94).

(1) GIBSON, James. La percepción del mundo visual. Buenos Aires: Ediciones Infinito, 1974.

(2) PARSONS, Ruth. The potencial influences of environmental perception on human health

In: Journal of Environmental Psychology n. 11, 1991.

(3) TUAN, Yi-fu.Topofilia: Umestudo da percepção, atitudes e valores do meio ambiente. São Paulo: Difel, 1980.

(4) CULLEN, Gordon. A paisagem urbana. Lisboa: Ediçōes 70, 1983.

(5) APPLEYARD, LYNCHK., MYERJ., D. The View from the Road _Cambridge(MA): M.I.T. Press, 1964.

(6) Para uma coletânea dos estudos de percepção no Brasil, ver: DEL RIO, V., OLIVEIRA, L. (org.) Percepção ambiental: A experiência brasileira. (lançamento previsto para 1995.)

(7) WALTER, Eugene Victor. Placeways: A theory of the human environment. Chapel Hill: The University of North Carolina Press, 1988.

(8) Vide. Desenho urbano e revitalização na área portuária do Rio de Janeiro: A contribuição do estudo da percepção ambiental. São Paulo, 1991. Tese (Doutorado) Faculdade de Arquitetura e Urbanismo, Universidade de São Paulo.

Vide. Revitalização de centros urbanos: O novo paradigma de desenvolvimento e seu modelo urbanístico. In: Revista Pós, São Paulo, n. 4, FAUUSP, dez. 1994.

(9) Sobre essaquestão veja-se nossoartigo A bela e a fera: Desenhourbanoe conflito deimagens In: Revista Projeto, n. 170, dez. 1993, e a pesquisa de Fernanda S. García. O city marketing de Curitiba, cultura e comunicação na construção da imagem urbana. In: DEL RIO, V., OLIVEIRA, L. (org.) op. cit.

(10) SENNET, Richard. The conscience of the eye: The design and social life of cities. New York: Norton, 1992.

(11) SORKIN, Michael. (Org.). Variations on a theme park: The new american city and the end of public space. New York: Nooday, 1992.

(12) VIRILIO, Paul. O espaço crítico. Rio de Janeiro: Editora 34, 1993. 